\title{
Synthesis, Crystal Structure, Spectra Characterization and DFT Studies on a Di-Cycle Pyrazoline Derivative
}

\author{
Jie Song, ${ }^{\dagger,}$ Pu Su Zhao, ${ }^{\dagger}, *$ and Wei Guang Zhang ${ }^{\dagger}$ \\ †Jiangsu Key Laboratory for Chemistry of Low-Dimensional Materials, Huaiyin Normal University, Huaian, Jiangsu, \\ 223300, P. R. China.*E-mail: zhaopusu@163.com \\ ${ }^{\ddagger}$ Materials Chemistry Laboratory, Nanjing University of Science and Technology, Nanjing, Jiansu, 210094, P. R. China \\ Received March 8, 2010, Accepted April 20, 2010
}

\begin{abstract}
A dicycle pyrazoline derivative, 1-phenyl-5-( $p$-fluorophenyl)-3,4-( $\alpha$ - $p$-fluoro-tolylenecyclohexano) pyrazoline, was synthesized and characterized by elemental analysis, IR, UV-vis, fluorescence spectra and X-ray single crystal diffraction. Density function theory (DFT) calculations were performed by using B3LYP method with 6-311G** basis set. The optimized geometry can well simulate the molecular structure. Vibrational frequencies were predicted, assigned and compared with the experimental values, which suggest that B3LYP/6-311G** method can well predict the IR spectra. Both the experimental electronic absorption spectra and the predicted ones by B3LYP/6-311G** method reveal three electron-transition bands, with the theoretical ones having some red shifts compared with the experimental data. Natural bond orbital analyses indicate that the absorption bands are mainly derived from the contribution of $n \rightarrow \pi^{*}$ and $\pi \rightarrow \pi^{*}$ transitions. Fluorescence spectra determination shows that the title compound can emit blue-light at about $478 \mathrm{~nm}$. On the basis of vibrational analysis, the thermodynamic properties of title compound at different temperature have been calculated, revealing the correlations between $C_{p, m}^{0}, S_{\mathrm{m}}^{0}, H_{m}^{0}$ and temperature.
\end{abstract}

Key Words: Crystal structure, Vibrational frequency, Electronic absorption spectra, Fluorescence spectra, DFT calculation

\section{Introduction}

Since Tang and Vanslyke first reported the usage of multilayer organic thin films for light-emitting devices (LEDs), ${ }^{1}$ organic electroluminescent devices (OELDs) have received considerable attention because of their potential applications in various displays. $^{2-4}$ The organic electroluminescence (OEL) devices have shown several advantages over inorganic ones, such as low cost, high luminous efficiency, wide selection of emission colors via molecular design of organic materials, and easy processing. Till now, a lot of works have been focused on blue color emitting materials. ${ }^{5-7}$

Pyrazoline derivatives have been investigated in many respects due to their blue light emission with high quantum yield, ${ }^{8-10}$ ready accessibility, and easily being used as carrier transporting as well as emitting materials. ${ }^{11}$ Many mono-cycle-2-pyrazolines have been reported as hole transporting or emitting materials in organic EL devices. ${ }^{12-15}$ From 2007, our group have focused attentions on investigating 1,3,5-triaryl-2-pyrazolines ${ }^{16-19}$ by experimental method and quantum chemical calculations. As a continuation of our previous studies in this field, we have also begun to synthesize di-cycle 2-pyrazolines in $2009 .{ }^{20}$ Herein, we wish to report another di-cycle 2-pyrazoline derivative of 1phenyl-5-( $p$-fluorophenyl)-3, 4-( $\alpha$ - $p$-fluorotolylenecyclohexano) pyrazoline, including its synthesis, structure, spectra studies and DFT calculations.

\section{Experimental and Theoretical Methods}

Physical measurements. Elemental analyses for carbon, hydrogen and nitrogen were performed by a Perkin-Elmer $240 \mathrm{C}$ elemental instrument. The melting points were determined on a

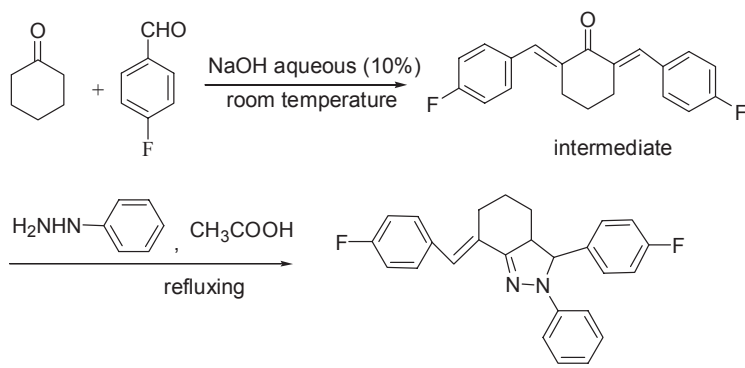

Scheme 1. The synthesis pathway of the title compound

Yanaco MP-500 melting point apparatus. IR spectra (4000 - 400 $\mathrm{cm}^{-1}$ ), as $\mathrm{KBr}$ pellets, were recorded on a Nicolet FT-IR spectrophotometer. Electronic absorption spectra were measured on a Shimadzu UV3100 spectrophotometer in EtOH solution and solid state fluorescence spectra were measured on a F96fluorospectrophotometer.

Synthesis. All chemicals were obtained from a commercial source and used without further purification.

The title compound was synthesized by two steps and the reaction path is shown in Scheme 1.

The first step is to synthesize the intermediate of 2, 6-bis(4fluorobenzylidene) cyclohexanone. To a $100 \mathrm{~mL}$ three-necked flask were added cyclohexanone $(0.03 \mathrm{~mol}), p$-fluorophenylaldehyde $(0.06 \mathrm{~mol}), \mathrm{NaOH}$ aqueous solution $(10 \%, 10 \mathrm{~mL})$ and $\mathrm{EtOH}(30 \mathrm{~mL})$ with stirring. After the reaction was carried out at room temperature for $1.5 \mathrm{~h}$, light-yellow intermediate was observed. $5 \mathrm{~h}$ later, the reaction was stopped and the intermediate was filtrated, washed with EtOH and then dried. Yield: $84 \%$.

The second step is to synthesize the title compound of 1phenyl-5-( $p$-fluorophenyl)-3,4-( $\alpha$ - $p$-fluorotolylenecyclohexa- 
no) pyrazoline. To a $100 \mathrm{~mL}$ three-necked flask were added the above synthesized intermediate $(0.01 \mathrm{~mol})$, phenylhydrazine $(0.03 \mathrm{~mol})$ and acetic acid $(30 \mathrm{~mL})$. The mixtures were heated and reaction was carried out under refluxing. $5 \mathrm{~h}$ later, the reaction was stopped and brown-yellow solution was poured in icewater to afford yellow solids. The solids were filtrated and washed with water until the $\mathrm{pH}$ of solution is about to 7 . Finally, the yellow solids were recrystallized by EtOH and dried under room temperature to afford the title compound. Yield 83\%. mp 165.9 - $166.7{ }^{\circ} \mathrm{C}$. Found: C, 77.85; H, 5.71 ; N, 6.87\%. Calc. for $\mathrm{C}_{26} \mathrm{H}_{22} \mathrm{~F}_{2} \mathrm{~N}_{2}$ : C, 77.96; H, 5.54; N, 7.00.

Crystal structure determination. The selected light yellow crystal of the title compound was mounted on an Enraf-Nonius CAD4 diffractometer. Reflection data were measured at 294(2) $\mathrm{K}$ using graphite monochromated $\operatorname{Mo~} \mathrm{K} \alpha(\lambda=0.71073 \AA)$ radiation and a $\omega-2 \theta$ scan mode. The correction for $L p$ factors and empirical absorption were applied to the data. The structure was solved by direct methods and refined by full-matrix least-squares method on $F_{\text {obs }}{ }^{2}$ using the SHELXTL software package. ${ }^{21}$ All non-H atoms were anisotropically refined. The hydrogen atom positions were fixed geometrically at calculated distances and allowed to ride on the parent $\mathrm{C}$ atoms. The final least-square cycle gave $R=0.0480, w R_{2}=0.1054$ for 1776 reflections with $I>2 \sigma(I)$ using the weighting scheme, $w=1 /\left[\sigma^{2}\left(F_{o}{ }^{2}\right)+(0.0688\right.$ $\left.P)^{2}\right]$, where $P=\left(F_{o}{ }^{2}+2 F_{c}{ }^{2}\right) / 3$. Atomic scattering factors and anomalous dispersion corrections were taken from International Table for X-ray Crystallography. ${ }^{22}$ The key crystallographic data are given in Table 1.

Computational methods. Initial molecular geometries were

Table 1. Summary of crystallographic results for the title compound

\begin{tabular}{ll}
\hline Empirical formula & $\mathrm{C}_{26} \mathrm{H}_{22} \mathrm{~F}_{2} \mathrm{~N}_{2}$ \\
\hline Formula weight & 400.46 \\
Temperature & $294(2) \mathrm{K}$ \\
Wavelength & $0.71073 \AA$ \\
Crystal system, space group & Monoclinic, $P 2(1) / \mathrm{n}$ \\
Unit cell dimensions & $a=5.4888(16) \AA$ \\
& $b=14.587(4) \AA$ \\
& $c=25.544(8) \AA$ \\
& $\beta=94.134(5)^{\circ}$ \\
Volume & $2039.9(11) \AA^{3}$ \\
$Z$, Calculated density & $4,1.304 \mathrm{Mg} / \mathrm{m}^{3}$ \\
Absorption coefficient & $0.089 \mathrm{~mm}{ }^{-1}$ \\
$F(000)$ & 840 \\
$\theta$ range for data collection & 1.60 to $25.02^{\circ}$ \\
Limiting indices & $-4 \leq h \leq 6,-17 \leq k \leq 13,-27 \leq l \leq 30$ \\
Reflections collected / unique & $7615 / 3603\left[R_{\text {int }}=0.0516\right]$ \\
Refinement method & Full-matrix least-squares on $F^{2}$ \\
Data / restraints / parameters & $3603 / 12 / 272$ \\
Goodness-of-fit on $F^{2}$ & 0.917 \\
Final $R$ indices $[I>2 \sigma(I)]$ & $R_{1}=0.0480, w R_{2}=0.1054$ \\
$R$ indices (all data) & $R_{1}=0.1255, w R_{2}=0.1441$ \\
Extinction coefficient & $0.0132(16)$ \\
Largest diff. peak and hole & 0.150 and -0.172 e. $\AA^{-3}$ \\
&
\end{tabular}

optimized using MM+ molecular modeling and semi-empirical AM1 methods ${ }^{23}$ (HYPERCHEM 6.0, Hypercube, Ont., Canada). Then, DFT calculations with a hybrid functional B3LYP (Becke's three parameter hybrid functional using the LYP correlation functional) at basis set $6-311 \mathrm{G}^{* *}$ by the Berny method ${ }^{24}$ were performed with the Gaussian 03 software package. ${ }^{25}$ The calculated vibrational frequencies ascertained that the structures were stable (no imaginary frequencies). Based on the optimized geometries and by using time-dependent density functional theory (TD-DFT) ${ }^{26-28}$ methods, electronic spectra were predicted. Natural Bond Orbital (NBO) ${ }^{29}$ analyses were also performed based on the optimized geometries.

All calculations were performed on a DELL PE 2850 server and a Pentium IV computer using the default convergence criteria.

\section{Results and Discussions}

Description for the crystal structure of the title compound. The displacement ellipsoid plot for the title compound with the numbering scheme is shown in Fig. 1. Selected bond lengths and bond angles by X-ray diffraction are listed in Table 2 along with the calculated bond parameters.

The molecular structure of the title compound consists of discrete $\left[\mathrm{FPhCHC}_{7} \mathrm{H}_{8} \mathrm{~N}_{2} \mathrm{PhPhF}\right]$ entities. All of the bond lengths and bond angles in the phenyl rings are in the normal range. In the cyclohexanopyrazolinyl ring, the $\mathrm{C}=\mathrm{N}$ bond length [1.287(3) $\AA]$ is slightly longer than those found in 1-phenyl-3-p-fluorophenyl-5-p-chlorophenyl-2-pyrazoline $[1.280(4) \AA]^{16}$ and 1phenyl-3- $p$-fluorophenyl-5-p-methoxyphenyl-2-pyrazoline $[1.286(3) \AA],{ }^{17}$ while the bond lengths of N-N and C-N are comparable to those with similar structures. ${ }^{16,17}$ Phenyl ring $[\mathrm{C}(1) \sim$ $\mathrm{C}(6)$ ] along with the attached $\mathrm{F}(1)$ and $\mathrm{C}(7)$ atoms define a plane $(P 1)$. Phenyl ring $[\mathrm{C}(15) \sim \mathrm{C}(20)]$ and atoms $\mathrm{F}(2)$ and $\mathrm{C}(14)$ define an another plane $(P 2)$. The dihedral angle between $P 1$ and $P 2$ is $39.62(2)^{\circ}$. The dihedral angles between the phenyl ring $[\mathrm{C}(21) \sim \mathrm{C}(26)]$ and the $P 1$ and $P 2$ are $75.32(2)^{\circ}$ and $85.09(2)^{\circ}$, respectively.

In the crystal lattice, there exist two $\mathrm{C}-\mathrm{H} \cdots \mathrm{N}$ hydrogen-bond supramolecular interactions. One is $\mathrm{C}(16)-\mathrm{H}(16) \cdots \mathrm{N}(2)$ interaction, with the $\mathrm{C}(16) \cdots \mathrm{N}(2)$ distance and $\mathrm{C}(16)-\mathrm{H}(16) \cdots \mathrm{N}(2)$ angle being 2.9181(2) $\AA$ and $100.76(1)^{\circ}$. Another is $\mathrm{C}(22)-\mathrm{H}(22) \cdots$ $\mathrm{N}(1)$ intreraction, with the $\mathrm{C}(22) \cdots \mathrm{N}(1)$ distance and $\mathrm{C}(22)$ $\mathrm{H}(22) \cdots \mathrm{N}(1)$ angle being $2.7401(2) \AA$ and $100.15(1)^{\circ}$. In the

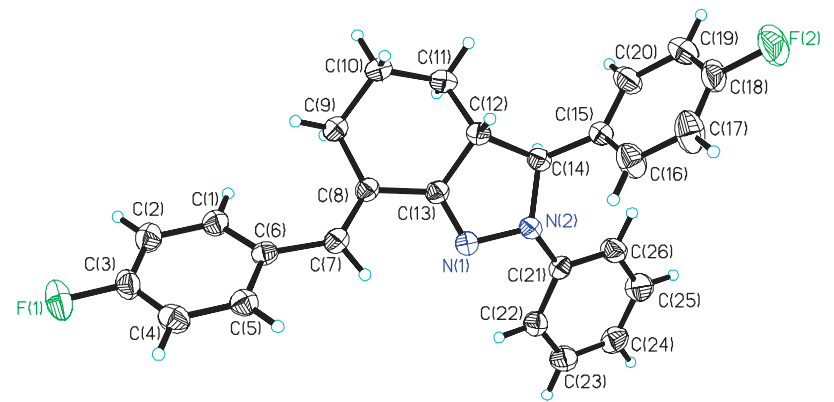

Figure 1. Molecular structure with the atomic numbering scheme for the title compound. 
Table 2. Selected geometric parameters by X-ray and theoretical calculations for the title compound at B3LYP/6-311G** level of theory

\begin{tabular}{|c|c|c|c|c|c|}
\hline Bond length $(\AA)$ & Exp. & Calc. & Bond length $(\AA)$ & Exp. & Calc. \\
\hline $\mathrm{F}(1)-\mathrm{C}(3)$ & $1.355(3)$ & 1.351 & $C(6)-C(7)$ & $1.473(4)$ & 1.466 \\
\hline $\mathrm{F}(2)-\mathrm{C}(18)$ & $1.358(3)$ & 1.352 & $C(8)-C(13)$ & $1.465(4)$ & 1.464 \\
\hline $\mathrm{N}(1)-\mathrm{C}(13)$ & $1.287(3)$ & 1.286 & $\mathrm{C}(13)-\mathrm{C}(12)$ & $1.496(3)$ & 1.511 \\
\hline $\mathrm{N}(1)-\mathrm{N}(2)$ & $1.398(3)$ & 1.383 & $C(10)-C(11)$ & $1.516(4)$ & 1.535 \\
\hline $\mathrm{N}(2)-\mathrm{C}(21)$ & $1.413(3)$ & 1.408 & $C(12)-C(14)$ & $1.536(3)$ & 1.549 \\
\hline $\mathrm{N}(2)-\mathrm{C}(14)$ & $1.477(3)$ & 1.484 & $C(15)-C(16)$ & $1.370(4)$ & 1.398 \\
\hline $\mathrm{C}(1)-\mathrm{C}(2)$ & $1.380(4)$ & 1.391 & $C(19)-C(20)$ & $1.384(4)$ & 1.393 \\
\hline$C(3)-C(4)$ & $1.361(4)$ & 1.387 & $C(21)-C(26)$ & $1.378(4)$ & 1.403 \\
\hline Bond angle $\left({ }^{\circ}\right)$ & Exp. & Calc. & Bond angle $\left({ }^{\circ}\right)$ & Exp. & Calc. \\
\hline $\mathrm{C}(13)-\mathrm{N}(1)-\mathrm{N}(2)$ & $108.2(2)$ & 109.5 & $\mathrm{~N}(1)-\mathrm{N}(2)-\mathrm{C}(14)$ & $111.1(19)$ & 111.2 \\
\hline $\mathrm{N}(2)-\mathrm{C}(14)-\mathrm{C}(12)$ & $101.8(2)$ & 101.2 & $\mathrm{~N}(1)-\mathrm{C}(13)-\mathrm{C}(12)$ & $114.2(2)$ & 113.1 \\
\hline$C(2)-C(1)-C(6)$ & $121.2(3)$ & 121.4 & $C(3)-C(4)-C(5)$ & $118.9(3)$ & 118.6 \\
\hline$C(8)-C(7)-C(6)$ & $130.4(3)$ & 129.8 & $\mathrm{C}(13)-\mathrm{C}(8)-\mathrm{C}(9)$ & $114.0(2)$ & 114.3 \\
\hline $\mathrm{C}(8)-\mathrm{C}(9)-\mathrm{C}(10)$ & $114.0(2)$ & 114.1 & $C(20)-C(15)-C(16)$ & $118.3(3)$ & 118.7 \\
\hline$C(18)-C(19)-C(20)$ & 119.2(3) & 118.6 & $\mathrm{C}(21)-\mathrm{C}(22)-\mathrm{C}(23)$ & $120.1(3)$ & 120.2 \\
\hline$C(24)-C(25)-C(26)$ & $120.8(3)$ & 120.9 & $\mathrm{C}(13)-\mathrm{C}(12)-\mathrm{C}(14)$ & $101.9(2)$ & 101.5 \\
\hline
\end{tabular}

solid state, these supramolecular interactions help to stabilize the crystal structure.

Optimized geometry. DFT-B3LYP/6-311G* calculations were performed on the title compound. Some optimized geometric parameters are also listed in Table 2. Comparisons of the experimental bond lengths with the calculated values show that the biggest bond length difference is $0.028 \AA$ for $\mathrm{C}(15)-\mathrm{C}(16)$ bond and the biggest bond angle difference is $1.3^{\circ}$ for $\mathrm{C}(13)$ $\mathrm{N}(1)-\mathrm{N}(2)$ bond angle. Both the differences are well comparable with those in mono-2-pyrazolines of $1 \mathrm{~N}$-phenyl-3-(3,4-dichlorophenyl)-5-phenyl-2-pyrazoline ${ }^{19}$ and $1 N$-phenyl-3-(2,4-dichlorophenyl)-5-(4-chlorophenyl)-2-pyrazoline, ${ }^{30}$ where the biggest difference of bond lengths and bond angles are $0.026 \AA$ and $1.3^{\circ}$ for the former ${ }^{19}$ and $0.027 \AA$ and $1.3^{\circ}$ for the later. ${ }^{30}$ As for the biggest bond difference on $\mathrm{C}(15)-\mathrm{C}(16)$ bond, which maybe result from two reasons: one reason is that all of the calculational data are for the molecule in gas phase and there are no molecular interactions considered, while the experimental data are for the molecules in solid state and there are crystal field interactions among them. Another reason is that there is a hydrogen-bond supramolecular interaction on $\mathrm{C}(16)-\mathrm{H}(16)$ bond, which will lead to the bond length of $\mathrm{C}(15)-\mathrm{C}(16)$ being shorter and increase the bond length difference between the theoretical value and the experimental one. Aforementioned comparisons suggest that, despite some differences, the B3LYP/ 6-311G** method can give satisfactory calculational precision for the system studied here. ${ }^{31}$ The optimized geometry obtained by B3LYP/6-311G* method can well reproduce the crystal structure of the title compound, which are the bases for the following discussions, such as the vibrational frequencies, electronic absorption spectra and thermodynamic properties and so on.

Vibrational frequencies. The experimental and the simulated infrared spectra are shown in Fig. 2, where the calculated intensity is plotted against the harmonic vibrational frequencies.

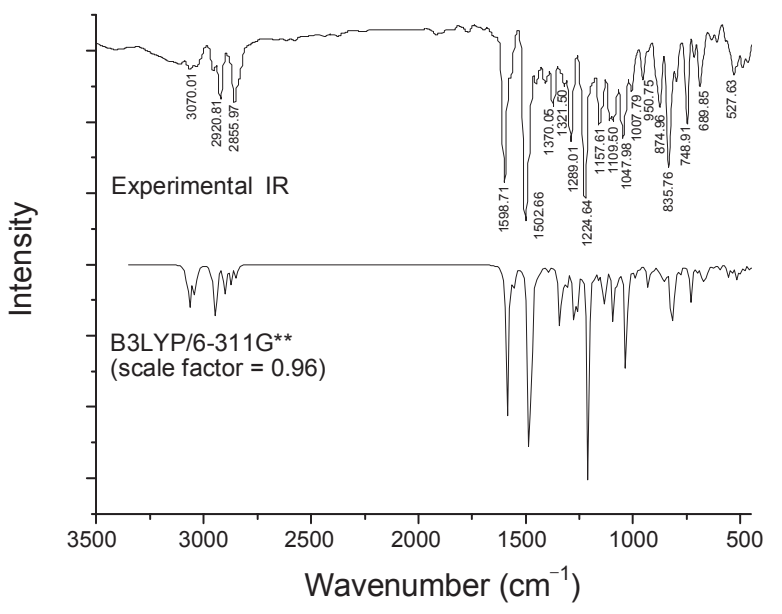

Figure 2. Experimental IR spectra (top) and predicted IR spectra at B3LYP/6-311G* level of theory (bottom) for the title compound.

Vibrational frequencies calculated at B3LYP/6-311G* level of theory were scaled by a typical scaled factor of 0.96 for this method. Some primary calculated harmonic frequencies are listed in Table 3 and compared with the experimental data. The descriptions concerning the assignment have also been indicated in the Table 3. Gauss-view program ${ }^{32}$ was used to assign the calculated harmonic frequencies.

As seen from Table 3 and Fig. 3, comparison of the differences between the experimental and calculational frequencies reveals a good agreement. Namely, for the title compound, in spite of some differences, DFT-B3LYP/6-311G** method used here can well predict the vibrational frequencies.

Electronic absorption spectra. For the title compound, experimental electronic absorption spectra are measured in ethanol solution at room temperature and theoretical electronic spectra are predicted by using TD-DFT method based on B3LYP/6- 
Table 3. Comparison of the observed and calculated vibrational spectra of the title compound ${ }^{a}$

\begin{tabular}{lcc}
\hline \multicolumn{1}{c}{ Assignments } & Exp. & $\begin{array}{c}\text { Calc. } \\
\text { (B3LYP/6-311G**) }\end{array}$ \\
\hline C-H str. in phenyl ring & 3070 & $3096-3034$ \\
C-H str. in methyl group & 2920 & 3022 \\
C-H str. in cyclohexano-pyrazoline group & 2856 & $2960-2847$ \\
C-C def. in phenyl rings & 1599 & $1589-1556$ \\
C-H def. in phenyl rings & 1503 & $1486-1473$ \\
C-H def. in methyl group & 1370 & 1348 \\
C-H def. in cyclohexano-pyrazoline group & 1322 & $1333-1324$ \\
C-H def. in phenyl rings and & 1289 & $1304-1272$ \\
cyclohexano-pyrazoline group & & \\
C-C def. in phenyl ring + C-F str. & 1225 & 1207 \\
C-C def. in phenyl ring + C-F str. & 1158 & $1201-1203$ \\
N-N str. + all of C-H def. & 1110 & 1094 \\
N-N str.+ C-N str. & 1048 & 1033 \\
C-C def. in cyclohexano-pyrazoline group & 1008 & 1013 \\
all of the C-H def. & 875 & $909-859$ \\
molecular skeleton def. & 845 & 850 \\
C-C def. in phenyl ring & 836 & 824 \\
molecular skeleton def. & 749 & 748 \\
C-H def.in phenyl ring & 690 & $700-697$ \\
molecular skeleton def. & 528 & 540 \\
\end{tabular}

${ }^{a}$ The atomic numbering scheme is as shown in Fig. 1. str.: stretch; def.: deformation

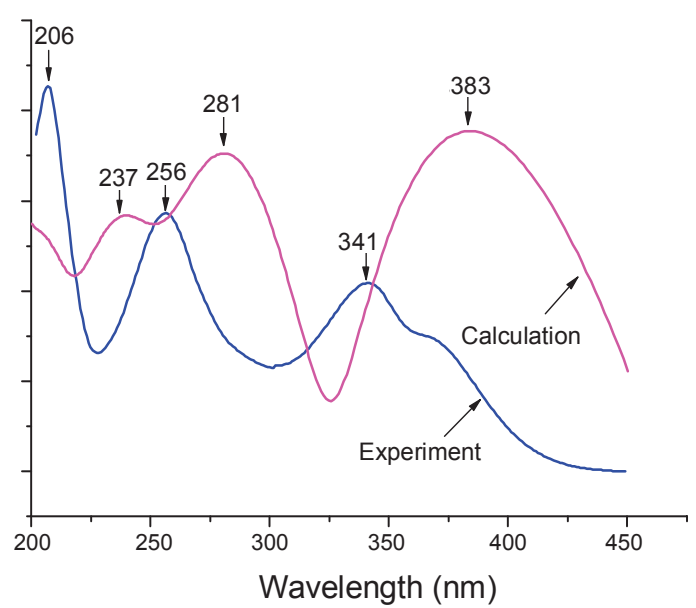

Figure 3. Experimental and theoretical electronic spectra for the title compound.

311G* level optimized structure. Both the electronic spectra are shown in Fig. 3 and all of the data are listed in Table 4 along with the electronic transition models.

As seen from Fig. 3 and Table 4, both the experiments and calculations reveal three bands, with three theoretical peaks having some red shifts compared with the corresponding experimental ones. The reasons for the discrepancy between the experimental values and theoretical predictions may be as follows: TD-DFT approach is based on the random-phase approximation (RPA) method, ${ }^{33-34}$ which provides an alternative to computationally
Table 4. Experimental and theoretical electronic absorption spectra values

\begin{tabular}{|c|c|c|c|}
\hline Exp. & & & Calc. (TD-DFT) \\
\hline $\begin{array}{l}\text { wave } \\
\text { length } \\
(\mathrm{nm})\end{array}$ & $\begin{array}{l}\text { wave } \\
\text { length } \\
(\mathrm{nm})\end{array}$ & $\begin{array}{l}\text { oscillator } \\
\text { strength }\end{array}$ & electronic transition \\
\hline 206 & 237 & 0.15 & $\begin{array}{l}105(\mathrm{HOMO}) \rightarrow 112(\mathrm{LUMO}+6) \\
100(\mathrm{HOMO}-5) \rightarrow 106(\mathrm{LUMO})\end{array}$ \\
\hline 256 & 281 & 0.37 & $\begin{array}{l}104(\mathrm{HOMO}-1) \rightarrow 106(\mathrm{LUMO}) \\
105(\mathrm{HOMO}) \rightarrow 110(\mathrm{LUMO}+4)\end{array}$ \\
\hline 341 & 383 & 0.56 & $105(\mathrm{HOMO}) \rightarrow 106(\mathrm{LUMO})$ \\
\hline
\end{tabular}

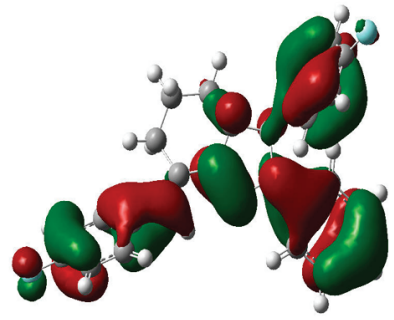

$100(\mathrm{HOMO}-5)$

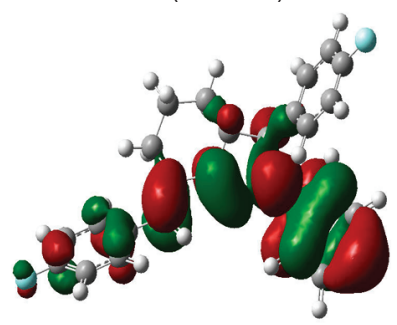

105 (HOMO)

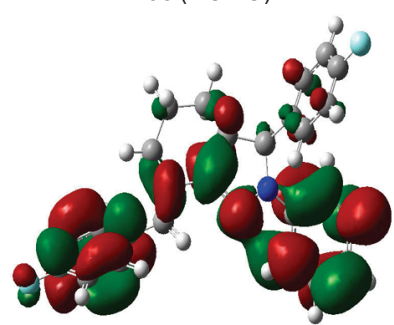

$110($ LUMO+4)

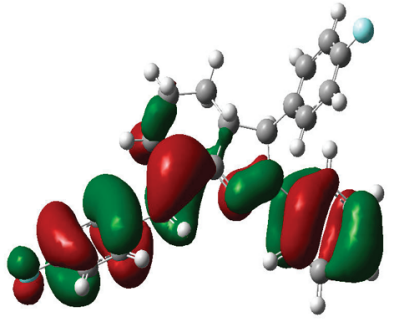

104 (HOMO-1)

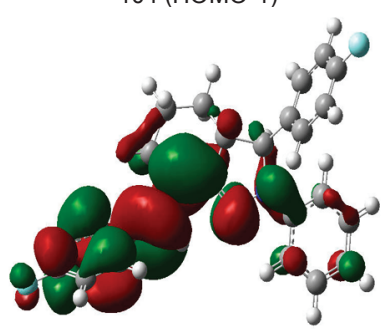

106 (LUMO)

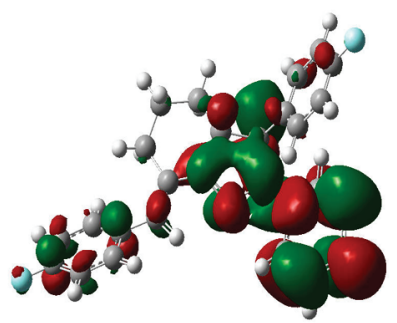

$112(\mathrm{LUMO}+6)$
Figure 4. Some frontier molecular orbital stereographs for the title compound.

demanding multirefrence configuration interaction methods in the study of excited states. TD-DFT calculations do not evaluate the spin-orbit splitting; the values are averaged. Here, in our paper, the objective is to evaluate the electronic structure by direct electronic excitations. Only singlet-singlet transitions are considered in these quasi-relativistic calculations. In addition, the role of the ethanol solvent effect of solution is not included in the theoretical calculations. Natural population analyses based on the B3LYP/6-311G** optimized geometry indicate that the frontier molecular orbitals are mainly composed of $p$ atomic orbitals, so electronic transitions corresponding to above electronic spectra are mainly assigned to $n \rightarrow \pi^{*}$ and $\pi \rightarrow \pi^{*}$ electronic transitions. Fig. 4 shows some frontier molecular orbital stereographs for the title compound. Seen from Fig. 4 and Table 4 , when electron transitions take place, electrons are mainly 


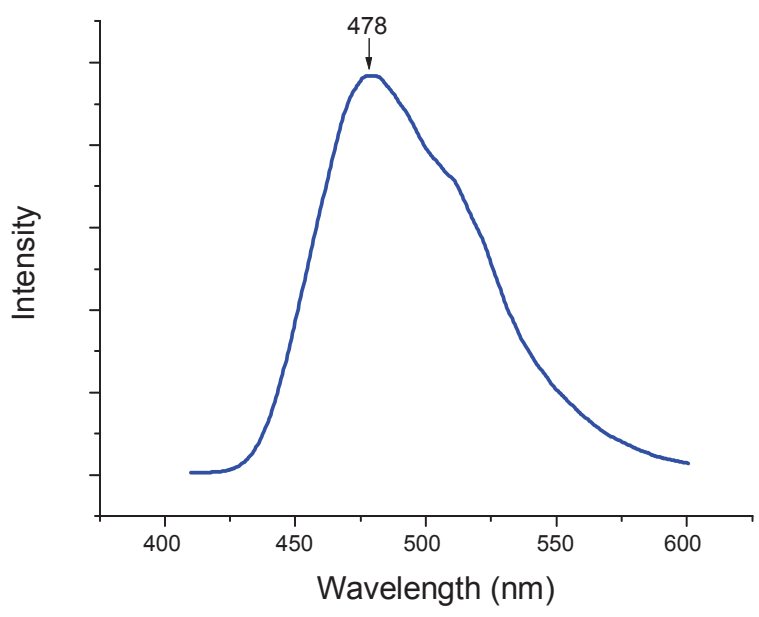

Figure 5. Solid-state fluorescence spectra of the title compound.

transferred among the two fluorophenyl rings, the phenyl ring and pyrazolinyl group, they are corresponding to the $n \rightarrow \pi^{*}$ and $\pi \rightarrow \pi^{*}$ electronic transitions.

Fluorescence spectra. The solid-state fluorescence spectrum of the title compound is shown in Fig. 5. The spectrum exhibits a maximum emission band at $478 \mathrm{~nm}$, which is in the blue-light region. This result suggests the title compound is a potential blue-light emitting material, which supports our original synthesized idea.

Thermodynamic properties. On the basis of B3LYP/6$311 \mathrm{G}^{* *}$ vibrational analysis and statistical thermodynamics, the standard thermodynamic functions: heat capacity $\left(C_{p, m}^{0}\right)$, entropy $\left(S_{m}^{0}\right)$ and enthalpy $\left(H^{0}{ }_{m}\right)$ were obtained. The scale factor for frequencies is still 0.96 .

Based on the calculations, all the values of $C_{p, m}^{0}, S_{m}^{0}$ and $H_{m}^{0}$ increase with the increase of temperature from 200.0 to $800.0 \mathrm{~K}$, which is attributed to the enhancement of the molecular vibration while the temperature increases. At room temperature, the values of $C_{p, m}^{0}, S_{m}^{0}$ and $H_{m}^{0}$ are $431.3 \mathrm{~J} \cdot \mathrm{mol}^{-1} \cdot \mathrm{K}^{-1}, 734.6 \mathrm{~J} \cdot \mathrm{mol}^{-1}$. $\mathrm{K}^{-1}$ and $68.2 \mathrm{~kJ} \cdot \mathrm{mol}^{-1}$, respectively.

In addition, on the base of the calculations, the correlative equations between these thermodynamic properties and temperature $T$ are obtained and listed as follows:

$$
\begin{aligned}
& C_{p, m}^{0}=-71.58+1.98 T-9.46 \times 10^{-4} T^{2}\left(R^{2}=0.99986\right) \\
& S^{0}{ }_{m}=273.77+1.64 T-2.90 \times 10^{-4} T^{2}\left(R^{2}=0.99995\right) \\
& H_{m}^{0}=-19.23+0.14 T+5.16 \times 10^{-4} T^{2}\left(R^{2}=0.9998\right)
\end{aligned}
$$

These equations could be used for the further studies on the title compound. For instance, when we investigate the interaction between the title compound and another compound, thermodynamic properties $C_{p, m}^{0}, H_{m}^{0}$ and $S_{m}^{0}$ could be obtained from these equations and then used to calculate the change of Gibbs free energy of the reaction, which will assist us to judge the spontaneity of the reaction.

\section{Conclusions}

The title compound of 1-phenyl-5-( $p$-fluorophenyl)-3,4-( $\alpha-p-$ fluoro-tolylene-cyclohexano) pyrazoline has been synthesized and characterized by elemental analysis, IR, UV-vis and X-ray single crystal diffraction. Solid-state fluorescence spectra are also measured, revealing a maximum emission peak at $478 \mathrm{~nm}$. B3LYP/6-311G**calculations for the title compound show that the optimized geometries closely resemble the crystal structure. The comparisons between the calculated results and the experimental data indicate the B3LYP/6-311G** method can well predict the vibrational frequencies. The predicted electronic spectra by TD-DFT method have three bands, which are corresponding with the experiments, although the theoretical electronic spectra have some red shifts compared with the experimental ones. NBO analyses suggest that the electronic spectra are mainly assigned to $n \rightarrow \pi^{*}$ and $\pi \rightarrow \pi^{*}$ electronic transitions. The correlations between the thermodynamic properties $C_{p, m}^{0}$, $S_{m}^{0}, H_{\mathrm{m}}^{0}$ and temperature $T$ are also obtained.

Supporting Information. CCDC-660447 contains the supplementary crystallographic data for this paper. These data can be obtained free of charge at www.ccdc.cam.ac.uk/conts/ retrieving.html [or from the Cambridge CrystallographicData Centre (CCDC), 12 Union Road, Cambridge CB2 1EZ, UK; fax: +44(0) 1222-336033; email: deposit@ccdc.cam.ac.uk].

Acknowledgments. This work was supported by Huaian Science \& Technology Bureau, Jiangsu Province, P. R. China (HAG09054-7), Fund of Huanyin Teachers College (08HSJSK003) and Fund of Jiangsu Key Laboratory for Chemistry of LowDimensional Materials (JSKC08047).

\section{References}

1. Tang, C. W.; VanSlyke, S. A. Appl. Phys. Lett. 1987, 51, 913.

2. Grüner, J.; Hamer, P. J.; Friend, R. H.; Huber, H. J.; Scherf, U.; Holmes, A. B. Adv. Mater. 1994, 6, 748.

3. Tasch, S.; Niko, S.; Leising, G.; Scherf, U. Appl. Phys. Lett. 1996, 68,1090 .

4. Greenham, N. C.; Moratti, S. C.; Bradly, D. D. C.; Friend, R. H.; Holmes, A. B. Nature 1993, 365, 628.

5. Salbeck, J.; Yu, N.; Bauer, J.; Weissortel, F.; Bestgen, H. Synth. Met. 1997, 91, 209.

6. Grice, A. W.; Tajbakhsh, A.; Burn, P. L.; Bradley, D. D. C. Adv. Mater. 1997, 9, 1174.

7. Gao, Z. Q.; Lee, C. S.; Bello, I.; Lee, S. T.; Chen, R. M.; Lu, T. Y. Appl. Phys. Lett. 1999, 74, 865.

8. Rivett, D. E.; Rosevear, J.; Wilshire, J. F. K. Aust. J. Chem. 1983, 36,1649

9. Wagner, A.; Schellhammer, C. W.; Petersen, S. Angew. Chem. Int. Ed. Engl. 1966, 5, 699.

10. Dorlars, H.; Schellhammer, C. W.; Schroeder, J. Angew. Chem. Int. Ed. Engl. 1975, 14, 665.

11. Sano, T.; Fujii, T.; Nishio, Y.; Hamada, Y.; Shibata, K.; Kuroki, K. Jpn. J. Appl. Phys. 1995, 34, 3124.

12. Ji, S. J.; Shi, H. B. Dyes. Pigments 2006, 70, 246.

13. Yang, G. B.; Wu, Y.; Tian, W. J.; Zhou, X.; Ren, A. M. Curr. Appl. Phys. 2005, 5, 327.

14. Lu, Z. Y.; Jiang, Q.; Zhu, W. G.; Xie, M. G.; Hou, Y. B.; Chen, X. H.; Wang, Z. J.; Zou, D. C.; Tsutsui, T. Synthetic. Met. 2000, 111112, 425 .

15. Wang, M. L.; Zhang, J. X.; Liu, J. Z.; Xu, C. X.; Ju, H. X. J. Lumin. 2002, 99, 79 .

16. Zhao, P. S.; Li, Y. F.; Guo, H. M.; Jian, F. F.; Wang, X. Bull. Koren. Chem. Soc. 2007, 28, 1539. 
17. Zhao, P. S.; Li, Y. F.; Guo, H. M.; Wang, X.; Jian, F. F. Polish J. Chem. 2007, 81, 1735.

18. Jian, F. F.; Zhao, P. S.; Guo, H. M.; Li, Y. F. Spectrochim. Acta A 2008, 69, 647.

19. Zhao, P. S.; Wang, H. Y.; Li, R. Q.; Guo, H. M. Indian J. Chem. A 2008, 47, 986 .

20. Guo, H. M.; Zhang, J.; Zhao, P. S.; Jian, F. F. Polish J. Chem. 2009, 83, 263.

21. Sheldrick, G. M. SHELXTL, v5 Reference Manual, Siemens Analytical X-Ray Systems, Madison: WI, 1997.

22. Wilson, A. J. International Table for X-Ray Crystallography, Kluwer Academic, Dordrecht, The Netherlands: 1992; Vol. C: Tables 6.1.1.4 (pp 500-502) and 4.2.6.8 (pp 219-222)

23. Dewar, M. J. S.; Zoebisch, E. G.; Healy, E. F. J. Am. Chem. Soc. 1985, 107, 3902

24. Peng, C.; Ayala, P. Y.; Schlegel, H. B.; Frisch, M. J. J. Comput. Chem. 1996, 49, 17.

25. Frisch, M. J.; Trucks, G. W.; Schlegel, H. B.; Scuseria, G. E.; Robb, M. A.; Cheeseman, J. R.; Montgomery, J. A.; Vreven, T., Jr.; Kudin, K. N.; Burant, J. C.; Millam, J. M.; Iyengar, S. S.; Tomasi, J.; Barone, V.; Mennucci, B.; Cossi, M.; Scalmani, G.; Rega, N.; Petersson, G. A.; Nakatsuji, H.; Hada, M.; Ehara, M.; Toyota, K.; Fukuda, R.; Hasegawa, J.; Ishida, M.; Nakajima, T.; Honda, Y.; Kitao, O.; Nakai, H.; Klene, M.; Li, X.; Knox, J. E.; Hratchian, H. P.; Cross, J. B.; Adamo, C.; Jaramillo, J.; Gomperts, R.; Stratmann,
R. E.; Yazyev, O.; Austin, A. J.; Cammi, R.; Pomelli, C.; Ochterski, J. W.; Ayala, P. Y.; Morokuma, K.; Voth, G. A.; Salvador, P.; Dannenberg, J. J.; Zakrzewski, V. G.; Dapprich, S.; Daniels, A. D.; Strain, M. C.; Farkas, O.; Malick, D. K.; Rabuck, A. D.; Raghavachari, K.; Foresman, J. B.; Ortiz, J. V.; Cui, Q.; Baboul, A.G.; Clifford, S.; Cioslowski, J.; Stefanov, B. B.; Liu, G.; Liashenko, A.; Piskorz, P.; Komaromi, I.; Martin, R. L.; Fox, D. J.; Keith, T.; AlLaham, M. A.; Peng, C. Y.; Nanayakkara, A.; Challacombe, M.; Gill, P. M. W.; Johnson, B.; Chen, W.; Wong, M. W.; Gonzalez, C.; Pople, J. A. Gaussian, Inc., Wallingford CT, 2004.

26. Runge, E.; Gross, E. K. U. Phys. Rev. Lett. 1984, 52, 997.

27. Petersilka, M.; Gossmann, U. J.; Gross, E. K. U. Phys. Rev. Lett. 1966, 76, 1212.

28. Bauernschmitt, R.; Ahlrichs, R. Chem. Phys. Let. 1996, 256, 1996.

29. Jamorski, C.; Casida, M. E.; Salahub, D. R. J. Chem. Phys. 1996, 104, 5134.

30. Zhao, P. S.; Guo, H. M.; Wang, X.; Jian, F. F. J. Chin. Chem. Soc. 2008, 183, 55 .

31. Jian, F. F.; Zhao, P. S.; Yu, Q.; Wang, Q. X.; Jiao, K. J. Phys. Chem. A 2004, 108, 5258 .

32. Frish, A.; Nielsen, A. B.; Holder, A. J. Gaussview Users Manual; Gaussian Inc.: Pittsburgh, 2003.

33. Olsenand, L.; Jorgensen, P. In Modern Electronic Structure Theory; World Science: Vol. 2, River Edge, NJ, 1995.

34. Fernando, M.; Claudio, O. A. Int. J. Quant. Chem. 2005, 103, 34. 